\title{
Implementation of Learning Strategies in the Classroom: A Case Study of Post-Graduate Diploma in Education (Pgde) Students at the University of Botswana
}

\author{
KeinyatseKgosidialwa $^{1^{*}}$, Mavis B. Mhlauli ${ }^{2}$, GolebamangGalegane ${ }^{3}$ \\ University of Botswana, Private Bag 00702, Gaborone, Botswana
}

*Corresponding Author: Keinyatse Kgosidialwa, University of Botswana, Private Bag 00702, Gaborone, Botswana

\begin{abstract}
Various factors have been found to contribute to the learners' performance during the schooling process. Due to low performance in schools of Botswana at both primary and secondary levels of education, it is critical to find the causes of this poor performance. One of the aspects to be considered is to interrogate how learners interact with the content material during the learning process. Hence, this case study explored the study strategies used by the Post Graduate Diploma in Education (PGDE) students because PGDE students will be graduating to be teachers and ready to serve in Botswana schools. For its theoretical framework the study uses the cognitive approach which basically stipulates taxonomy of learning strategies(Weinstein and Mayer, 1986).From a population of 160 PGDE students from the University of Botswana, a group of 20 students(15 females and 5 males) voluntarily participated in the study. The participants responded to the interview questions a week before they sat for their final examinations in order to ascertain their readiness for the world of work. Data were analyzed thematically based on the research questions. The findings show that the students know and use a variety of study strategies and the most commonly used strategy was making short notes to capture what they have been studying and asking themselves questions, followed by re-reading while others even though few, reported using strategies such as highlighting and revision of past examination papers. The study recommended that teacher educators have to reinvent themselves by putting more emphasis on learning strategies as they prepare their student-teachers in order to equip them with lifelong skills and be metacognitive about their strategies right from the early ages at primary school level.
\end{abstract}

Keywords: Post Graduate Diploma, Education, students, learning strategies, study strategies, university, Botswana, teacher education.

\section{INTRODUCTION}

Student assessment has long been considered as one of the key issues in education as it assists educators to know if students have learnt what they were taught (Mhlauli and Kgosidialwa, 2016). Through assessment learner's academic performance have been found to be influenced by various factors which among others include their learning aptitude, motivation, and the technics or strategies learners use to learn. The impact of such factors seem not to differ whether the learner is at primary, secondary or tertiary level of education. For example, when learners are motivated to do their work and understand the material they stand a better chance to perform well. However, some learners are less motivated in their school work, others are challenged academically, and some use study strategies or techniques that are less effective and do not enhance their learning. Slavin (2012) concurs with this view; "many students do poorly in school because they have failed to learn how to learn" (p.386). Slavin further suggests that strategies used by students have an impact on their academic performance; therefore, it would be beneficial if educators have a clear understanding of the strategies used by the learners in studying the materials at various levels of education.

There are a number of explanations regarding what study strategies are. In trying to explain what the aforementioned are, Eggen and Kauchak (2013) stated that "Study strategies are specific techniques students use to increase their understanding of the written material and teacher presentations" (p.271).On the other hand, "learning strategies are viewed as procedures that facilitate a learning task in which the learner is often conscious and goal-driven' (Chamot, 2005:112). In fact,Mayer(1988) had 
earlier explained learning strategies as behaviors that are intended to influence how the learner processes the material to be learnt."In cognitive science...the term 'strategy' has been referred to as a small range of synonyms such as 'technique', 'tactic' and 'skills', by which individual researchers describe their understandings in this particular area in slightly differential ways" (Liang, 2009. p.1). Different researchers in the area of learning strategies refer to these strategies differently despite their reference to the same activities that learners engage in to interact with the material in the process of learning. Dunlosky, Rawson, Marsh, Nathan and Willingham (2013) refer to them as "learning techniques", while Hartwig \& Dunlosky (2012) call them study strategies. In this study we use 'learning strategies' and study strategies interchangeably also to embrace both the techniques and tactics that learners use to study the learning materials when preparing for a test or examination. Understanding the learning strategies that students employ while studying can assist because when the teacher understand the learners' capabilities and limitation then they would be in a better position to effectively assist them (Schutz, Gallagher and Tepe, 2011).

\subsection{Problem Statement}

In his keynote speech, the Director, UNESCO-IICBA in Vavrus, Thomas and Barlett (2011) vehemently emphasized that "the relationship between the learner, teacher, and materials is the heart of education quality" (p.5).This relationship emphasizes the importance of understanding how the learner interacts with the material in the learning process, because studies show that some study strategies have a positive influence on performance than others (Jung., Choi., Lim., andLeem, 2002; Gurung,2005; Hurst., Wallace., Nixon, 2013).Since PGDE students are pre-service teachers who will be completing their teacher-training program at the end of a particular year of study, it would be of paramount importance to explore their learning strategies. The expectation is that as future teachers, they will inculcate the knowledge and skill usage of learning strategies amongst their students. In addition, despite the extensive existence of literature onstudy strategies used by learners in the western world. For example, Braten and Olaussen (1998) cited several studies conducted to investigate the strategies decades ago (King, Gibbs and Lipsky, 1984; Weinstein and Mayer, 1986)in the western culture. However, up until now, no research (according to our knowledge) exists in Botswana that investigated the study strategies employed by students at any level of schooling. Weinstein (1994) emphatically pointed out that understanding learning strategies of students should be central to the implementation of appropriate instructional interventions. This notion is further upheld by Braten and Olaussen (1998) who pointed out the need to understand the strategies used by students of different cultural backgrounds and further as they pointed out which students' strategy use may be related to their academic performance. Hence, there is need to find out if learners know and use the strategies when preparing for the tests and examinations. This case study intended to explore the knowledge and usage of study strategies by students, in this case being the Post Graduate Diploma in Education (PGDE) students in the University of Botswana.

\subsection{Purpose of the Study}

The purpose of this case study is to explore the learning strategies used by Post Graduate Diploma in Education (PDGE) students at the University of Botswana, and also suggest possible learning strategies that could be used by students to enhance their studies. In addition, the study intends to make recommendations of how to implement such strategies in studying.

\subsection{Research Questions (RQs)}

The study was guided by the following Research Questions:

- What learning strategies do Post Graduate Diploma in Education (PGDE) students at the University of Botswana use to enhance their learning?

- What are the PGDE students' understanding of the importance of learning strategies?

- What suggestions (if any) are needed to improve the PDGE students' experiences on learning strategies?

\subsection{Theoretical Framework}

Educators need to understand how their students interact and understand the material in the learning process in order for them to teach effectively and for the learners to benefit from their instruction. 
Research suggests a relationship between motivation, strategy use and academic performance (Albaili, 1997). The theoretical framework of this study is anchored on the cognitive approach as proposed by Weinstein \& Mayer (1986), and further developed by Mckeachie, et. al. (1986). Mckeachie et.al. (1986) designed a taxonomy of learning strategies. The taxonomy comprises of three components namely; cognitive, metacognitive and resource management (Filcher \& Miller, 2000). The cognitive approach to learning posits a relationship between the use of strategies and the learner's academic performance. The theory suggests the more the learners use the learning strategies the more they are likely to perform better academically as they understand their capability. The use of cognitive approach cannot be separated from the metacognitive component in which learners are aware of the strategies that work for them. The cognitive approach is more relevant to the current study as it focuses more on the activities that learners engage in to process the learning material (Vermunt $\&$ Vermetten, 2004). Some of the cognitive strategies in the model proposed by Mckeachie et al., (1986), include rehearsal, elaboration, and organization (Filcher \& Miller, 2000. P.62). The cognitive approach believe students who use more of the strategies are more effective in learning (Albaili, 1997). In addition, Weinstein et.al (1987) designed a Learning and Study Strategies Inventory scale (LASSI). This scale measures the various aspects of a learner such as motivation, self -management and cognitive strategies. The cognitive scales deal with how the learners process the information as demonstrated by activities such as selecting main ideas, self-testing, paraphrasing, summarizing, and elaborated learning to name a few. The use of learning strategies is believed to improve on information processing and its retention. Hence, this theoretical framework is aligned to this study as learning strategies or study strategies are crucial skills that learners need to possess if effective learning is to happen in a learning environment.

\section{LITERATURE REVIEW}

There are several strategies that students in the process of studying use to understand the learning material. These strategies include; note taking, using text signals, summarizing, elaborative questioning, and concept mapping (Eggen and Kauchak, 2013). From a more specific point of view, Zimmerman (1998a) cited in Ruban, McCoach, McGuire and Reis (2003) had earlier pointed out that, not all strategies are effective in learning. Zimmerman gave an example of strategies such as memorization which he believed could result in students getting good grades, despite not being able to generalize beyond classroom or academic learning. In fact, Karpicke, Butler and Roediger (2009)had long pointed out that research in memory has demonstrated that repetitive reading is not an effective strategy in promoting learning. On the other hand, Eggen and Kauchak (2013) concur with this view by asserting that learners who are anxious about the test in most cases engage in less effective study strategies such as memorization as compared to effective strategies.

A number of scholars explained the different types of strategies used by students in different contexts. Iqbal, Sohail and Shahzad (2010) conducted a study on learning and study strategies used by university students in Pakistan, and the findings showed that students scored better on self-testing. However, the students were found to be weak on a couple of strategies such as selecting the main ideas. In another study, Gurung (2005) had college students describe the strategies they use in preparing for an Introductory Psychology Course Examination. Gurung's findings indicated that more students reported using practice testing which also correlated with their performance on their final examinations.

Hartwig and Dunlosky (2012) investigated the study habits of 324 undergraduate students as well as their college grade point average (GPA). The data collection instrument had items on 'self-testing, scheduling one's study, and a checklist among other strategies. The findings showed self-testing as a relatively popular strategy and positively correlated to student achievement. In fact, earlier on in a study with the intentions to compare the effectiveness of summarizing and self-testing as learning strategies among 87 college students, King, Biggs and Lipsky (1984) found that summarizing as a study strategy was able to enhance free recall and improve performance on objective tests, while selftesting was effective on objective test but not on free recall. On the other hand, Woolfolk(1998) suggested that underlining and note taking were the two most commonly used strategies among college students. 
Dunlosky et al. (2013) evaluated ten study techniques which are commonly used by students being: elaborative interrogation, self-explanation, summarization writing, keyword mnemonic, imagery for text, rereading, practice testing: self-testing, distributed practice and interleaved practice (Dunlosky, et al., 2013, p.6). The findings of the study showed that students were mostly dependent on rereading and highlighting. The two study strategies according to Dunlosky and his co-authors do not promote effective learning. Nevertheless, effective strategies such as practice testing were found to be employed by some few students. Dunlosky et al. further pointed out that some effective learning strategies were underutilized as many teachers do not put them into practice, therefore resulting in many students not using them either due to lack of knowledge or their own unwillingness (Dunlosky et al.2013).

In a response to the rhetoric on why students do not use study strategies, Hartwig and Dunlosky(2012) pointed out that students may have not been taught about either the techniques which are effective or even how to use them effectively during the learning process. Hartwig and Dunlosky also further suggested that teachers might not be knowledgeable of various learning strategies that exist. Eggen and Kauchak (2013) pointed out that effective use of the strategy depends on the learners' motivation and ability. The learning goals of the classroom have also been found to influence the strategies used to study the material. When students perceive their classroom to be mastery-goal orientated they are likely to report using effective learning strategies and believe that putting effort would lead to success (Ames and Archer, 1988). This implies that some learners use strategies which may be effective in their learning while others may use others strategies that are less effective depending on how they interpret the goal of the class or the teacher. Despite the fact that, students may have fewer learning strategies to use, and the goals of the class may not influence them as they have no other alternatives.

In fact, earlier on Oxford (2002) indicated how knowledge of learning strategies need to be inculcated in students' learning material and further suggested the following:

- Strategy training should form an integral part of regular classroom events

- Strategy instruction should be embedded in meaningful communicative contexts.

- Students should be taught how to identify and analyze their preferred learning strategies by means of diaries, learning journals, interviews, and surveys.

- Teachers should provide explicit explanation and modeling of strategy use and provide ample opportunities for practice.

- Teachers should be aware that strategy training takes time. It may take months or even years to be able to use learning strategies effectively.

In his final recommendations, Oxford (2002) advised teachers to continuously conduct research in their own classrooms to better understand the numerous factors which affect the choice and skillful use of learning strategies by their learners.

\section{RESEARCH METHODOLOGY}

The study is qualitative and uses an instrumental case study design. Qualitative inquiry was chosen primarily because it allows for studying people in whatever setting one encounters them (Patton, 1990) and in this case the students' use of study strategies by PGDE students at the University of Botswana.

\subsection{Research Design}

Case study as a research design has the potential to examine a complex phenomenon by narrowing it down to a manageable level, hence suitable for this study. This study used an instrumental case study design because it typically examines an issue in an effort to provide insight or to redraw a generalization (Denzin and Lincoln, 2003). This case study was descriptive in nature and was used in order to explore the study strategies used by PGDE students at the University of Botswana. This design was chosen as it would enable the researchers to explicitly explain in depth the contexts within which these strategies are used by PGDE students at the University of Botswana. An instrumental case study design was found to be suitable for this study as it enables a researcher to closely examine 
the data within a specific context (Denzin and Lincoln, 2003). This type of case study provides a holistic detailed information about the phenomena being studied.

\subsection{Participants}

The PDGE program is a one year program through which degree holders from other faculties other than Education could come and get the teaching experience(be trained and qualified) as educators in their own specialized area. Hence, these student-teachers hold their degrees from various areas such as Humanities, Business, and Social Science A sample of twenty (20) student-teachers, fifteen (15) females and five (5) males, from a population of a hundred and sixty student-teachers enrolled in the Post Graduate Diploma in Education (PGDE) program in the academic year 2018/19. The studentteachers above voluntarily participated in the study. The participants had been taking an Educational Psychology course offered by one of the authors. The imbalanced proportion of male and female in the sample emanates from the imbalance of the two genders in the PGDE program at the University of Botswana, with more females as compared to their male counterparts. The participants' age ranged from twenty-seven (27yrs) to thirty-three (33yrs). None of the participants had taught prior to coming for training. The participants held a four-year degree from different programs in the University of Botswana. 15\% had a Bachelor in Education (Family \& Consumer Science,10\% from BA Humanities (Media Studies), 40\%Bachelors in Education (Geography and English) and another $35 \%$ pre-service teachers had BA Humanities (African Languages).

\subsection{Research Instruments}

Several studies investigating learning or study strategies and their contribution to academic performance have relied on Weinstein, Palmer and Shulte (2002) Learning and Study Strategies Inventory (LASSI).However, unlike prior researchers, this study neither used the readymade instruments such as LASSI nor the Motivated Strategies Learning Questionnaire (MLSQ) originally developed by Pintrich, Smith, Gracia and Mckeachie. This study is exploratory in nature and a more relevant open-ended instrument was designed to capture the variations in learning strategies. In the current study the instrument comprised of interview question that were divided in two parts. Section A gathered the biographical data while Section B gathered data on student learning strategies and their perception on academic performance. Questions for Section B were formulated from the research questions where students reported on the learning strategies they used to study for tests and examinations. The questions were designed to retrieve a self-report like data based on the research questions. Although Chamot (2005) posits that self-reports had the potential to be subjective and stand the chance of being erroneous. The scholar goes further to suggest that up to now there was no better method that exists for objectively identifying learners' learning strategies when learning a task as this involves the unobservable mental processes (Chamot, 2005).Interview questions were used for this study because they were suitable to solicit data that the study needed (Corbin\& Strauss, 1990).

\subsection{Data Collection and Analysis}

Before the participants responded to the semi structured interview questions, they were informed about the study, its intentions and their consent to participate was sought. The participants were also assured that their identity would be kept confidential and anonymous by not including their names or anything that can reveal their identity within the study. Additionally, the participants were also informed about how their participation or withdrawal would not prejudice them in anyway. However, students responded to written interview questions at their own time and submitted after a week. Data were analyzed inductively by the researchers independent of each other. Through coding and categorizing themes were developed, the researchers converged to compare and improve on the themes for triangulation purposes (Strauss and Corbin, 1998) and align the themes to the research questions.

\section{FINDINGS AND DISCUSSIONS}

This study sought to explore the students' use of learning strategies in their studies and how they implemented them in their learning. It also had intentions to proffer suggestions that could be made to improve the PGDE experiences on learning strategies. The findings of the study are presented and discussed using themes that emerged from the research questions. The themes are divided into two categories that fall under the Research Questions (RQs)with sub-themes which are discussed as: 
knowledge of learning strategies, implementation of learning strategies, increases in student performance, levels of exposure to learning strategies, exposure to learning strategies.

\section{Theme 1: Study Strategies Used by PGDE Students at the University of Botswana?}

The findings of the study reflect a gloomy picture in relation to students 'implementation of learning strategies in their studies, hence there is need for a paradigm shift in the teaching and learning among the PGDE students. It was clear that the student-teachers knew of a variety of strategies to use when they study either for tests or examinations. The sub-themes below discuss in detail the students' views on the strategies they use in their studies.

\section{Sub- Theme1.1: Knowledge of learning strategies}

It became apparent that student teachers do have knowledge of the strategies that they could utilize to enhance their learning. The results indicate that students use strategies such as making short notes, rereading, self- testing, memorization, group discussion, revision of past examination papers. However, based on their level of education one would expect them to mention a plethora of learning strategies which can be used to interact with the material.

\section{Sub-Theme 1.2: Implementation of Learning Strategies}

When asked to list the strategies they always use to interact with the material when preparing for the examination and/or test. The findings showed that students' usage of strategies varied, some students indicated their knowledge of strategies and the level at which they implemented the strategies, however some students usage of strategies was limited as they indicated they used them sometimes and not always. Few strategies such as making short notes, rereading and group discussions were commonly used. Below are a few extracts from the participants' interviews on what they do when studying:

Participant 1:"Normally I study in a quite environment especially during the night. I make short notes as I read and set questions for myself."

Participant 2: "I read the whole document, then I close it and try to remember what I just went through also note whatever I am studying”

Participant 3: "I read the notes first then make my short according to what I have understood while reading" said the participant.

Participant 4:I use group discussions".

From the four responses above, the findings suggest that the students use a number of study strategies such as reading, making notes and group discussions. These strategies could help the students to understand more about the different topics that they study in their PGDE program. Referring to reading as a study strategy, it can be deduced that the students do a lot of reading because they are required in their different PGDE courses to read before, during and after class. Further, the group discussions are used to help the students to share ideas and in the end, promoting learner-centered approach. The above findings are similar to Eggen and Kauchak(2013) who also observed that strategies such as note-taking help the students to understand the learning material.

The second strategy, which was mentioned by the participants, was the short quizzes. The short quizzes, just like the strategies discussed above help the students to understand the subject matter. However, the self-quizzes go further to help the students to think of possible test/examination questions and have an idea of their performance. It can be concluded that the aforementioned strategy is good because it helps the students to prepare for their assessments. It is interesting to note that the above results are in line with Hartwig and Dunlosky's (2012) observation. The above two scholars observed that self-testing was a relatively popular strategy that positively correlated with the students' achievement.

From the above findings on the students' strategies that they used, it can be concluded that the participants' educational level requires that they use a number of learning strategies. However, when asked about these, their responses were below the expectations. For example, one would expect them to mention strategies such as "concept mapping, SQ4R" and many others. These concerns have been 
noted by scholars such as Avalos (2000) who cited Torres (1996) where he emphatically pointed out that many students do not know the learning strategies hence, they need to be helped to learn how to learn. Few participants in this study indicated using underlining, highlighting or marking the material while preparing for the test or examination unlike in Dunlosky et al., (2013) where underlining, highlighting or marking material in the process of studying have been reported as common strategies and appealing to students due to their simplicity. The different findings on the use of underlining and highlighting, as stated above, could add to the literature that different strategies are used differently by the heterogeneous groups of students.

Concluding the above findings, it is evident that learning strategies differ in their contribution to students' learning and academic performance. For example, Chamot (2005) posits how a particular learning strategy can help a learner in a certain context to achieve learning goals and another strategy may not be very effective in learning the same material. Instructors who are aware of learning strategies may be able to enhance student learning outcomes, regardless of student knowledge (Morehead, Rhodes and DeLozier, 2016).Woolfolk (1998) had emphasized that students be exposed to a variety of learning strategies and tactics in order for them to be effective learners.

\section{Theme 2: PGDE Students' Understanding of the Importance of Study Strategies}

When it comes to their views on the importance of the learning strategies. The findings show that majority of the participants indicated that the use of strategies in learning is important to every learner.

\section{Sub-Theme 2.1: Increases academic performance}

All the participants pointed out that knowledge and usage of learning strategies is very crucial when preparing for the tests or examinations, and its contribution to overall academic performance. Participants believe and understand the importance of learning strategies in enhancing performance, in addition they also pointed out idea of saving time as well as their contribution in knowledge retention. The following are anecdotes from some of participants:

Participant 7:Strategies help students recall what they learnt therefore increase academic performance

Participant 4: It saves time and allows for students to focus on what is important in what have learnt.

Participant 16: The strategies help an individual to manage and use their time for important things and good understanding.

The findings in this study are in tandem with those of Ames \& Archer (1988) who contend that if effective learning strategies are used by the students, there would be success in the teaching and learning process which ultimately leads to improved academic performance.

\section{Sub-Theme2.2: Levels of exposure to learning strategies}

Despite the importance of the learning strategies as indicated in the above findings of the study, there was a response to the question that solicited for the educational level where the participants were taught the study strategies and how they acquired them. The findings showed that most of the participants indicated that learnt the strategies at the tertiary and senior secondary school level. For example, in response to a question that requested to know the level of education at which the participant started using learning strategies one of the participants had this to say: "I learnt to use learning strategies when doing my Diploma in Theology in 2012." The preceding results could be as a result of the fact that it is at tertiary learning where the students need to demonstrate a number of strategies. This is because at tertiary there are a lot of courses taken hence a call for more intensive study strategies. A very small number of the participants learnt the strategies at junior and primary school level. As indicated earlier, the minimal use of the study strategies could be due to limited knowledge of the strategies by the students.

\section{Sub-Theme 2.3: Exposure to learning strategies}

In their response to how they learnt the learning strategies, the findings showed that participants have learnt the strategies from various sources such as classmates, themselves and very few from their 
educators. Majority of the participants showed that they had learnt these strategies on their own. These findings of this study differs from Morehead, Rhodes and DeLozier (2016) instead of 2014 study where minority claimed that they were not taught study techniques by the educators or had learnt them by themselves. Even though few of the participants in this study indicated minimal usage of the study strategies during their primary/junior secondary schooling, and none of them had learnt the use of strategies from the teachers.

\section{CONCLUSIONS AND RECOMMENDATIONS}

The purpose of this case study was to explore the learning strategies used by Post Graduate Diploma in Education (PDGE) students at the University of Botswana. One of the major findings was that the students use a number of study strategies such as reading, making notes and group discussions, and these help the students to understand more about the different topics that they study in their PGDE program. Another outcome from this study was that the students-teachers' use of a number of learning strategies was below the expected standard. Furthermore, the study concluded that the use of strategies promotes academic performance. Finally, the student-teachers showed that they had learnt the different study strategies on their own without the help of their instructors and they learnt them late during their schooling process despite research purporting evidence in the literature on how study strategies enhance free re-call (King, Biggs and Lipsky (1984).

\section{RECOMMENDATIONS}

Based on the above conclusions, this study has the following recommendations:

- Teacher educators have to put emphasis on assisting students to develop the ability to use a variety of study strategies.

- That teacher educators expose and train student teachers in study strategies so that they too can teach their learners how to study effectively as that can promote their learning skills and promote their awareness of their awareness.

- Students have to take responsibility of their learning through implementing what they have learned for future use.

\section{Implications for Research and Practice}

This study provides information on learning strategies used by PGDE students at the University of Botswana and has the potential to influence practice, research and policy formulation on teaching and learning in general. The findings in this study have implications for student teachers, teacher educators and students generally. The study lays a foundation on teacher education, action and collaborative research in order to enhance their knowledge and pedagogical base. Furthermore, the study is probably the first of its kind at this level of education in Botswana, therefore, forms a baseline for re-thinking about teaching and learning strategies at post graduate levels among teachers and student teachers as a whole in Botswana.

\section{REFERENCES}

[1] Albaili, M.A. (1997).Differences among low-, average- and high-achieving college students on learning and study strategies. Educational Psychology, 17 (1 \& 2,), 171-177.

[2] Ames,C., \&Archer, J.(1988). Achievement goals in the classroom: Students' learning strategies and motivation process. Journal of Educational Psychology, 80 (3), 260-267.

[3] Avalos, B.(2000).Policies for teacher education in developing Countries. International Journal of Educational Research, 33, 457-474.

[4] Braten, I., \&Olaussen, B.S. (1998).The learning and study strategies of Norwegian first -year college students. Learning and Individual Differences, 10(4), 309-327.

[5] Chamot, A.U. (2005) Language learning strategies instruction Current Issues and Research. Annual Review of Applied Linguistics, 25, 112-130.

[6] Corbin, J. \& Strauss, A. (1990). Grounded Theory Research: Procedures Canons and Evaluative Criteria.Qualitative Sociology, 13(1),1-13.Qualitative Sociology, Vol. 13,

[7] Denzin, N.K. \& Lincoln, Y.S. (2003).Strategies of qualitative inquiry ( $\left.2^{\text {nd }} e d.\right)$. London: Sage. 
[8] Dunlosky, J., Rawson,K.A., Marsh, E. J., Nathan, M. J., \& Willingham, D. T. (2013). Improving students' learning with effective learning techniques: Promising directions from cognitive and educational psychology: Psychological Science in the Public Interest, 14(1), 4-58.DOI: 10.1177/15291006124532: lhttp://pspi.sagepub.com.

[9] Eggen, P, \&Kauchak, D. (2013). Educational Psychology: Windows on classrooms.Columbus: Pearson.

[10] Filcher, C \& Miller, G. (2000).Learning strategies for distance education students. Journal of Agricultural Education, 41 (1), 60-68.

[11] Grabe, W. (2002). Dilemmas for the development of second language reading abilities. In Richards \&Renandya(Eds).Methodology in Language teaching: An Anthology of Current Practice. Cape Town: Cambridge University Press.

[12] Gurung, A. R. (2005).How do students really study (and Does It Matter)? Teaching of Psychology, 32(4), 238-240.

[13] Hartwig, \&Dunlosky, J. (2012). Study strategies of college students: Are self-testing and scheduling related to achievement? Psychology Bulletin Review, 19(1), 126-134.

[14] Hurst, H., Wallace, R., \&Nixon, S. (2013). The impact of social interaction on student learning. Reading Horizons: A journal of literacy and language arts, 52 (4), 375- 398.

[15] Iqbal, H.M., Sohail, S.,\&Shahzad, S. (2010) Learning and study strategies used by university students in Pakistan. Procedia Social and Behavioral Sciences, 2, 4717-4721.

[16] Jung, I., Choi, S., Lim, L., \&Leem, L. (2002). Effects of different types of interaction on learning achievement, satisfaction and participation in web-based instruction.Innovations in Education and Teaching International, 39 (2), 153-162.

[17] Karpicke, J, D. Butler, A.C \&Roediger III H.L (2009) Metacognitive strategies in students learning. Do students practice retrieval when they study on their own? Memory 17(4), 471-479.

[18] Morehead, K., Rhodes, M.G., \& DeLozier, S. (2016). Instructor and student knowledge of study strategies. Memory, 24(2), 257-271, DOI:10.1080/09658211.2014.1001992.

[19] King, J. R. Biggs, S \&Lipsky, S. (1984). Students' Self - Questioning and Summarizing as Reading Study Strategies. Journal of Reading Behavior, 16 (3), 206-217.

[20] Liang, T. (2009).Language learning strategies: The theoretical framework and some suggestions for learner training practice. English Language Teaching.2 (4), 199-206.

[21] Mazumder, Q. H., \&Dakeev, U. (2015). A comparative study of motivation and learning strategies between high school and university students. A paper presented at 122 ASEE Annual Conference \& Exposition Seattle, 14-27 June, 2015.

[22] Mayer, R.E. (1988) Learning strategies: An overview. In Weinstein, C. E. Goetz, E \& Alexander P. (Eds.), Learning and study strategies: Issues in assessment, instruction, and evaluation. San Diego, CA: Academic Press.

[23] Merriam, S. B. (2009). Qualitative research: A guide to design and implementation (2nd ed.). San Francisco, CA: Jossey-Bass.

[24] Mhlauli, B. M. \& Kgosidialwa, K. (2016). The Use of a Portfolio to enhance Authentic Assessment among In-service Student-Teachers' in Social Studies Education at the University of Botswana. Journal of Education and Human Development, 5(3), 84-96 DOI: 10.1 5640/jehd.v5n3a10

[25] Oxford, R.L. (2002).Language learning strategies in a Nutshell: Update and ESL suggestions in Richards, J.C. \&Renandya, W. A. (2002). Methodology in language teaching: An anthology of current practices. New York: Cambridge University Press.

[26] Patton, M. Q. (1990). Qualitative evaluation and research methods ( $2^{\text {nd }}$ Ed). Newbury Park: Sage.

[27] Ruban, L.M., McCoach, D. B., McGuire, J.M., \&Reis, S.M. (2003). The differential Impact of academic self-regulation methods on academic achievement among university students with and without learning disabilities. Journal of Learning Disabilities, 36(3), 270-286.

[28] Schutz, C.M., Gallagher, M.L. \&Tepe, R.E.(2011) Differences in learning and study strategies inventory scores between chiropractic students with lower and higher grade point averages, The journal of Chiropractic Education, 25(1).5-10.

[29] Slavin, R.E. (2012). Educational psychology: Theory and Practice. Cape Town: Pearson.

[30] Strauss, A \&Corbin, J. (1998).Basics of qualitative research: Techniques and procedures of developing grounded theory. California: Sage Publishers.

[31] Vermunt, J.D. and Vermetten, Y.J. (2004).Patterns in student learning: Relationships between learning strategies, conceptions of learning, and learning orientations. Psychology Review, 16(4), 359-384. 
Implementation of Learning Strategies in the Classroom: A Case Study of Post-Graduate Diploma in Education (Pgde) Students at the University of Botswana

[32] Weinstein, C. E. \& Mayer, R.E. (1986).The Teaching of learning strategie. In Wittrock, M. C. Handbook of Research on Teaching, 315-327: New York: Macillan.

[33] Weinstein C.E, Palmer D. R, Schulte A. C. (2002).Learning and study strategies inventory (2nd Ed.). Clearwater, FL: H \& H Publishing Company, Inc.

[34] Woolfolk, A. E.(1998). Educational psychology. Tokyo: Allyn\& Bacon.

Citation: KeinyatseKgosidialwal, et.al. "Implementation of Learning Strategies in the Classroom: A Case Study of Post-Graduate Diploma in Education (Pgde) Students at the University of Botswana". International Journal of Humanities Social Sciences and Education (IJHSSE), vol. 6, no.12, 2019, pp. 65-74. doi: http://dx. doi.org/10.20431/2349-0381.0612005.

Copyright: (C) 2019 Authors. This is an open-access article distributed under the terms of the Creative Commons Attribution License, which permits unrestricted use, distribution, and reproduction in any medium, provided the original author and source are credited. 